\title{
Spinal subdural haematoma in von Willebrand disease
}

\author{
Artur Franko ${ }^{1}$, Ronald Antulov ${ }^{1}$, Siniša Dunatov ${ }^{2}$, Igor Antončić ${ }^{2}$, Damir Miletić1 \\ ${ }^{1}$ Department of Radiology, ${ }^{2}$ Department of Neurology, \\ Clinical Hospital Centre Rijeka, Rijeka, Croatia
}

\begin{abstract}
Background. Von Wilebrand disease (vWD) is the most common inherited disorder of hemostasis. Bleeding in patients with von Wilebrand disease is a frequently reported complaint. Patients with inherited bleeding disorders are also in a large number of cases infected with hepatitis C virus (HCV). Studies showed an increased risk factor for intracerebral hemorrhage (ICH) in patients infected with HCV receiving the combination treatment.
\end{abstract}

Case report. A 44-year old man reported to our Emergency Department with low back pain, headaches, neck pain, leg weakness and urinary retention. The neurological examination showed nuchal rigidity and spastic paraparesis. Thoracic spine MRI revealed a subacute subdural haematoma at T8-T11 level.

Conclusions. To the best of our knowledge, this is the first report of a subdural haematoma of the thoracic spine in a patient with $\mathrm{WWD}$ and chronic HCV infection. The presented patient was receiving a combination treatment, a fact that has also to be taken in consideration as a possible risk factor for a bleeding episode.

Key words: von Willebrand disease; subdural haematoma; hepatitis C; complications of treatment; interferon; ribavirin

\section{Introduction}

Von Wilebrand disease (vWD) is an inherited bleeding disorder that results from quantitative and qualitative deficiencies of von Wilebrand factor (vWF), a glycoprotein with an essential role in primary and secondary hemostasis. ${ }^{1}$ vWD is the most common inherited bleeding disorder, with

Received 23 December 2008

Accepted 23 March 2009

Correspondence to: Damir Miletić, MD, PhD, Department of Radiology, Clinical Hospital Centre Rijeka, Krešimirova 42, 51000 Rijeka, Croatia; Phone: +385 (0)51 658 862; Fax. +385 (0)51 658 386; E-mail: damir.miletic@medri.hr a prevalence from $0.6 \%$ to $1.2 \% .^{2}$ Patients with vWD are prone to complain of different bleeding episodes like mucocutaneus bleeding, menorrhagia, gastrointestinal bleeding with angiodysplasia or excessive postsurgical bleeding. ${ }^{1}$ The infection with hepatitis $\mathrm{C}$ virus (HCV) is a major comorbidity in patients affected by bleeding disorders, with a prevalence of $39 \%$ in vWD patients. ${ }^{3}$ In patients with chronic $\mathrm{HCV}$ infection the combination therapy of pegylated interferon alpha- $2 \mathrm{~b}$ and ribavirin is becoming a standard treatment. ${ }^{4}$ Recent studies suggested that patients with chronic $\mathrm{HCV}$ infection receiving combination therapy were more prone to develop an intracerebral haemorrhage $(\mathrm{ICH})$, indicating 
a possible association between $\mathrm{HCV}, \mathrm{HCV}$ treatment and $\mathrm{ICH}^{5}{ }^{5} 6$

Spinal subdural hematoma (SSDH) is a rare condition that can lead to spinal cord or cauda equina compression. ${ }^{7}$ A variety of causes, like bleeding disorders, anticoagulant therapy, arteriovenous malformations or underlying neoplasm have been described as possible pathogenic factors that could promote the formation of an acute SSDH. ${ }^{8}$ Therefore, SSDH is a neurological and neurosurgical emergency that has to be promptly diagnosed and treated in order to provide the best possible recovery.

We report on a 44-year old man with vWD and chronic HCV receiving the combination therapy that developed sudden leg weakness and low back pain as the initial presentation of spontaneous acute SSDH. The diagnosis was confirmed by MRI and the patient was treated with a conservative approach.

Here we discuss the clinical features, imaging findings, treatment decision and outcome.

\section{Case report}

A 44-year old man reported to our Emergency Department (ED) with acute low back pain, headaches, neck pain, leg weakness and urinary retention. During the last two days before he reported to our ED, the patient had high body temperature. Since childhood, he was diagnosed vWD. He was serologically diagnosed as infected with HCV in 1999, and had been treated with the combination therapy of pegylated interferon alpha- $2 \mathrm{~b}$ and ribavirin for a period of five months before he reported to our ED. A month and a half before this episode, he was admitted to our Gastroenterology Department because of a bleeding duodenal ulcer. There was no history of trauma.
The physical examination showed blood pressure $100 / 60 \mathrm{~mm} \mathrm{Hg}$, pulse $88 / \mathrm{min}$ and body temperature of $37.7{ }^{\circ} \mathrm{C}$. The neurological examination showed nuchal rigidity and spastic paraparesis of the legs. The blood test revealed a platelet count of $89.000 / \mathrm{mm}^{3}$, a prothrombin time of $65 \%$ and a partial thromboplastin time of $54 \mathrm{~s}$. Laboratory studies for vWD showed a factor VIII activity of $43 \%$ and a vWF activity (ristocetin factor) of $17 \%$. A MRI of the thoracic spine revealed a high intensity signal in T1- and T2-weighted images (WI) extending from T8 to T11 that belonged to a dorsal subdural haematoma. There was no abnormal signal visible in the spinal cord (Figure 1). The treatment was conservative and cryoprecipitates were administered according to the level of factor VIII and vWF activity. The antiviral combination therapy was withdrawn. The patient responded well to our therapy and physiotherapy treatment followed after the initial mobilization.

After a month, on discharge from our centre, the patient was able to sit independently and his neurological improvement was satisfactory. On a follow-up MRI scan done 3 months after he reported to our ED there was a complete regression of the subdural hematoma and the neurological examination was normal.

\section{Discussion}

Acute SSDH is a rare condition that may result from iatrogenic factors, but also from coagulopathies, anticoagulant therapy, severe liver failure, underlying neoplasm, arteriovenous malformations or after poisoning with rodenticides of the coumarin group. ${ }^{8-10}$ It usually presents with acute back pain and signs of spinal cord and cauda equina compression. Bleeding episodes often accompany $\mathrm{vWD}$, but they rarely lead to the formation of a hematoma. ${ }^{1}$ In two 



Figure 1A, B, C, D. Sagital T2-WI (A), sagital T1-WI (B), axial T2-WI (C) and axial T1-WI (D) showing a T1 and T2 high intensity signal dorsal spinal subdural haematoma.

cases, patients with vWD reported with a subgaleal hematoma and an encapsulated hematoma of the thigh, both of them occurring after a trauma. ${ }^{11,12}$

Our patient with SSDH and vWD did not have any recent history of trauma, but he was on combination therapy for chronic $\mathrm{HCV}$ infection. Recent studies and case reports suggested that HCV infection alone or with combination therapy raised the possibility to develop an ICH. 5,6,13 Taking this in consideration, we could hypothesize that chronic HCV infection and combination therapy could be a risk factor to develop SSDH. Therefore, we decided to withdraw the antiviral combination therapy from his treatment.

MRI is the imaging method of choice to determine the location, evolution, extent and shape of the hematoma, as well as the follow-up of the patient like at the patients with the others causes of spine cord compresion. ${ }^{9,10,14,15}$ Our patient had a dorsal hematoma, with a crescent shape, extending from T8 to T11 and a high intensity signal in T1- and T2-weighted images indicating a hematoma in the subacute phase. The epidural fat was well delineated, a fact that confirms the subdural location of the hematoma. Follow-up MRI scans were done in order to asses the evolution of the hemato$\mathrm{ma}$, that in our case in a 3 months period showed a complete regression, and to look for possible long term complications represented by arachnoidal fibrosis or spinal cord atrophy. ${ }^{10}$

The current literature suggests three treatment options in case of a subdural hematoma: surgical decompression, percutaneous clot drainage and conservative treatment. ${ }^{9,10,14}$ In a previous case of a subdural hematoma in a patient with idiopathic thrombocytopenic purpura a conservative approach was preferred, because of a significant risk of bleeding. ${ }^{16}$ Because our patient was diagnosed with vWD, a factor that could promote bleeding complications during a surgical procedure, we opted for a conservative treatment.

Reviewing the literature regarding spinal hematoma and vWD, Kakazu et al. ${ }^{17}$ reported of a spontaneous spinal epidural haem- 
orrhage associated with vWD. Therefore, to the best of our knowledge, this is the first report of a subdural hematoma of the thoracic spine in a patient with vWD and chronic HCV infection under the combination therapy. Our patient had an indicative clinical presentation, the diagnosis was confirmed by MRI and we decide to pursue a conservative treatment approach. We withdrew the antiviral combination therapy because of the possibility that it could be a risk factor for spontaneous bleeding. After three months, our patient showed a complete recovery.

\section{References}

1. Ewenstein BM. Von Willebrand's disease. Аnпu Rev Med 1997; 48: 525-42.

2. Rodeghiero F, Castaman G, Dini E. Epidemiological investigation of the prevalence of von Willebrand's disease. Blood 1987; 69: 454-9.

3. Federici $A B$, Santagostino E, Rumi MG, Russo A, Mancuso ME, Soffredini R, et al. The natural history of hepatitis $\mathrm{C}$ virus infection in Italian patients with von Willebrand's disease: a cohort study. Haematologica 2006; 91: 503-8.

4. Manns MP, McHutchison JG, Gordon SC, Rustgi VK, Shiffman M, Reindollar R, et al. Peginterferon alfa-2b plus ribavirin compared with interferon alfa- $2 b$ plus ribavirin for initial treatment of chronic hepatitis $\mathrm{C}$ : a randomised trial. Lancet 2001; 358(9286): 958-65.

5. Ferencz S, Batey R. Intracerebral haemorrhage and hepatitis C treatment. J Viral Hepat 2003; 10: $401-3$

6. Nishiofuku M, Tsujimoto T, Matsumura Y, Toyohara M, Yoshiji $\mathrm{H}$, Yamao J, et al. Intracerebral hemorrhage in a patient receiving combination therapy of pegylated interferon alpha-2b and ribavirin for chronic hepatitis C. Intern Med 2006; 45: 483-4.

7. Langmayr JJ, Ortler M, Dessl A, Twerdy K, Aichner F, Felber S. Management of spontaneous extramedullary spinal haematomas: results in eight patients after MRI diagnosis and surgical decompression. J Neurol Neurosurg Psychiatry 1995; 59: 442-7.
8. Domenicucci M, Ramieri A, Ciappetta P, Delfini R. Nontraumatic acute spinal subdural hematoma: report of five cases and review of the literature. J Neurosurg 1999; 91(Suppl 1): 65-73.

9. Boukobza M, Haddar D, Boissonet M, Merland JJ. Spinal subdural haematoma: a study of three cases. Clin Radiol 2001; 56: 475-80.

10. Morandi X, Riffaud L, Chabert E, Brassier G. Acute nontraumatic spinal subdural hematomas in three patients. Spine 2001; 26: E547-51.

11. Raffini L, Tsarouhas N. Subgaleal hematoma from hair braiding leads to the diagnosis of von Willebrand disease. Pediatr Emerg Care 2004; 20: 316-8.

12. Wexler S, Edgar M, Thomas A, Learmonth I, Scott G. Pseudotumour in von Willebrand disease. Haemophilia 2001; 7: 592-4.

13. Karibe H, Niizuma H, Ohyama H, Shirane $R$, Yoshimoto T. Hepatitis C virus (HCV) infection as a risk factor for spontaneous intracerebral hemorrhage: hospital based case-control study. J Clin Neurosci 2001; 8: 423-5.

14. Kyriakides AE, Lalam RK, El Masry WS. Acute spontaneous spinal subdural hematoma presenting as paraplegia: a rare case. Spine 2007; 32: E619-622.

15. Rajer M, Kovač V. Malignant spinal cord compression. Radiol Oncol 2008; 42: 23-31.

16. Benito-Leon J, Leon PG, Ferreiro A, Martinez J. Intracranial hypertension syndrome as an unusual form of presentation of spinal subarachnoid haemorrhage and subdural haematoma. Acta Neurochir (Wien) 1997; 139: 261-2.

17. Kakazu K, Ohira N, Ojima T, Oshida M, Akiyama $\mathrm{M}$, Horaguchi M, et al. Extensive spinal epidural hemorrhage associated with von Willebrand's disease - a case report. Nippon Seikeigeka Gakkai Zasshi 1980; 54: 501-5. 